
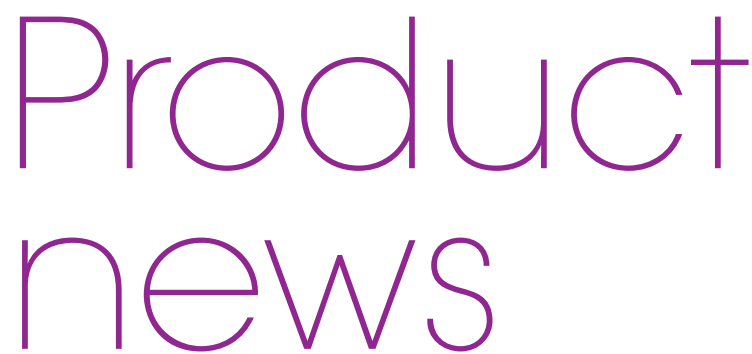

Product news is provided as a service to readers using text and images from

the manufacturer, supplier or distributor and does not imply endorsement

by BDJ Team. Normal and prudent research should be exercised before

purchase or use of any product mentioned.

\section{GET IN THE KNOW AT BDIA DENTAL SHOWCASE 2015}

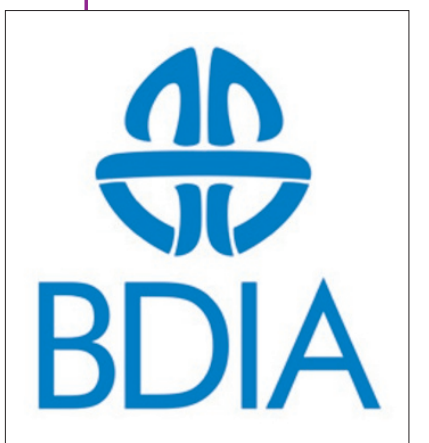

Every member of the team at your practice will have their specialisms and particular areas of interest. That's why BDIA Dental Showcase is the must attend event of the year.

Taking place at the Birmingham

NEC between 22-24 October 2015, Dental

Showcase brings together the biggest and best names in the dental world and lets every member of the team meet with on-stand experts presenting the largest selection of equipment, technologies, products and services of any dental trade show.

BDIA Dental Showcase is the most established and best attended show in the dental calendar. Whether you're a dentist, practice manager, hygienist, therapist, dental nurse, lab owner, dental technician or dental receptionist, the show has something for everyone.

Along with the product and service innovations, BDIA Dental Showcase 2015 has an extensive programme of CPD mini lectures, presentations and interactive demonstrations where you can discover the latest thinking in a wide range of subjects. There will be over 350 exhibitors demonstrating the latest technologies, techniques and services, making it the ideal event to discuss with on-stand experts how the latest innovations can benefit you, your practice and your patients. Not only will the established global brands be attending, but also many specialist and overseas companies will be looking to share their knowledge and expertise with you.

This year, Dental Showcase is delighted to present an expanded series of free verifiable
CPD mini lectures. These lectures and demonstrations are presented by leading industry experts and last around 20 minutes. There's a wide selection to choose from, with many of direct interest to dental nurses, and others that will help expand your knowledge of other aspects of the business of dentistry.

In addition to the lecture programme, there are dozens of on-stand presentations and practical demonstrations where you'll be able to learn about the latest products and techniques. This year there is also the new Dietary Zone, sponsored by The Dairy Council, in which you can discover more about the relationship between nutrition and oral health and how you can help patients by providing appropriate advice. Many recruiters and careers advisers will be present, allowing you the chance to discuss how you can enhance your career prospects and possibly find a new job.

As well as attending lectures and topping up your CPD, the Dental Showcase is the ideal place to catch up with old friends and meet new colleagues. Many associations will have stands and hosting events, including the British Association of Dental Nurses, the National Examining Board for Dental Nurses, and the Orthodontic Technicians Association.

BDIA Dental Showcase is all about sharing ideas and know-how. And you can share your thoughts with lots of your colleagues, because this year the British Society of Dental Hygiene and Therapy will feature a special member's day on the Friday of the show, located next to the Showcase entrance at Hall 5. Delegates will all receive fast track entry to Showcase and we look forward to welcoming them to the exhibition.

The lectures are on a strictly first come first served basis. So, make sure you plan ahead and take a look at the full programme by visiting www.dentalshowcase.com.
DEVICE PROVIDES DAYTIME TREATMENT FOR TMJ

Cerezen, a first-of-its-kind medical device that is a safe and effective aid in reducing Temporomandibular Joint Disorder (TMJD) pain and associated symptoms such as grinding of teeth and headaches, is available in the UK and Ireland, and will be on display at the BDIA, stand K5. The device consists of two custom-made. hollow ear canal inserts that allow full passage of sound and are practically invisible from the outside. Traditionally. TMJD has been treated with bite splints that are worn at night, and because the Cerezen device is comfortable and discreet, it makes daytime patient compliance easy

The Cerezen device takes a different approach in treating TMJD. The ear canal is located very close to the temporomandibular joint (TMJ) and the volume of the ear canal increases when the jaw is opened through movements such as chewing, smiling, and speaking The Cerezen device uses this anatomical change to provide a unique near field treatment for TMJD.

Patients wearing the device in a three month clinical study experienced a significant reduction in the pain and dysfunction associated with TMJD. In addition to the pain reduction, 100\% of subjects indicated excellent (71\%) or good (29\%) overall satisfaction with the Cerezen device.

During a three month clinical study, patients wearing the Cerezen device did not report any unexpected or serious adverse events and a comparable safety profile to the stabilisation splint was observed. It is not recommended that patients wear the Cerezen device while bathing, swimming or in a moist environment such as a steam bath and sauna. It is recommended that the Cerezen device be removed when participating in contact sports

For more information about the device. visit www.cerezen.eu.

If you would like to promote your products or services direct to the dental industry in BDJ Team, call Andy May on 02078434785 or emaila.may@nature.com 